Check for updates

London, UK

Cite this as: BMJ 2021;373:n1039 http://dx.doi.org/10.1136/bmj.n1039 Published: 11 May 2021

\section{Supporting teams through the pandemic: nephrologist Reza Motazed}

\section{Nephrologist and clinical director Reza Motazed tells Adrian 0'Dowd how the covid-19 pandemic has inspired his team to work more closely than ever}

Adrian O'Dowd

Times of adversity can bring out the best in people, and the work of the healthcare team at Croydon Health Services NHS Trust during the covid-19 pandemic has left Reza Motazed feeling increasingly proud to work there.

Since the pandemic began, the consultant acute physician, nephrologist, and clinical director for integrated adult care has led daily online meetings for all staff within the hospital's clinical services to discuss covid matters. "I'm available for anyone who wants to join our meeting to raise any concerns," he says. "We discuss the covid numbers; where we are with ventilation, staffing, and rotas; and make sure staff are empowered to make changes in terms of the way they work.

“The meeting is useful because people don't have time to read emails. Even though the covid numbers have come down, we're carrying on with these meetings because we now have to concentrate on our patients who are unwell without covid."

Motazed thinks that it's important for people within an organisation to support each other, wherever or whoever they are. "We've had a lot of tears in the past 12 months and a lot of people who have lost a loved one. The only way we can survive this is respecting and communicating with each other," he says.

Motazed qualified from St George's Hospital Medical School in London in 1996 and started working at Croydon University Hospital as a substantive consultant in 2013. He says one of the main reasons he wanted to become a doctor was "to be able to make a difference in a person's life, by giving them the right clinical care and having an impact on their wellbeing." Motazed chose nephrology as a specialty because he felt it allowed him to make a difference to his patients. "People with kidney failure are quite vulnerable patients-working as a junior doctor in a renal unit, you could see that-and following these patients up in the clinic you actually became quite close," he says.

As well as his role as a clinical nephrologist, Motazed is the clinical director for integrated adult care at his trust. "I've been proud to be the clinical director within adult care for Croydon while we went through the first and second wave of covid," he says. "During the past year, one thing I've learnt is that it doesn't matter if you are a consultant, a junior doctor, a nurse, a phlebotomist, a physio, a cleaner, or a security officer-we are all in the same boat."

Motazed said he is extremely proud of what the staff at the hospital have achieved. "At one point we were caring for 30 or more patients on our general wards who needed non-invasive ventilation, freeing up much needed capacity within our intensive care unit for the most seriously ill.

"We did this more than any other trust I know, with the support of our consultants, nurses, juniors, and managers, and as a result Croydon is now up for an excellence in patient care award from the Royal College of Physicians.”

As for what advice he would give to a newly qualified doctor, he says, "You've gone through a lot of training to be where you are, so as a doctor and as a healthcare professional you should see your position as a privilege."

\section{Nominated by Priyank Shah}

"Dr Motazed always goes the extra mile for his patients and colleagues. He has been an incredible mentor to me and helped me through a stressful period when my dad was in hospital with covid.

"He has given me so much encouragement during my training; he has become family to me. He is a brilliant role model-he runs a daily covid meeting for any member of hospital staff to attend and has done so since the first wave hit. Each day he takes on the concerns of staff and helps to solve their problems. These meetings have brought together healthcare professionals from all walks of life."

Priyank Shah is a second year foundation trainee at Croydon University Hospital 